\title{
Impact of organizational culture, satisfaction of employees and students on the quality of education in University of Civil Engineering
}

\author{
Mikhail Leontev ${ }^{1, *}$ \\ ${ }^{1}$ Moscow State University of Civil Engineering, Yaroslavskoe sh., 26, 129337, Moscow, Russia
}

\begin{abstract}
The educational sphere is undergoing significant changes, the focus is on the competitiveness and customer service. This study examined the role of organizational culture, satisfaction of job and education in quality assurance of education and quality service of customers of the University of civil engineering. In this study three measuring methods are applied. The first one focused on the measurement of the components of organizational culture, and the second one evaluated the job satisfaction of employees, the third one measured the level of satisfaction of learners. The workers of the University highly evaluated follow indicators of job satisfaction: the opportunity to be busy all the time, the ability to work alone, the opportunity to do something for others and the ability to perform a various types of work. They gave more importance to the quality of services provided to students, and the importance of these services for the university. The correlation between organizational culture and satisfaction of students was significant. Unlike employees, students showed greater consistency in the positive perception of the university and positively evaluated its activities a whole.
\end{abstract}

\section{Introduction}

The objectives of this study can be formulated as follows: to identify a connection between the components of organizational culture and job satisfaction of employees of the university; to identify the relationship between job satisfaction of employees of university and satisfaction of learners; to identify a link between satisfaction of learners and components of organizational culture. The quality of education at the University in this study is considered in connection with the components of organizational culture.

The environment in which educational institutions and universities operate, in is becoming more dynamic in recent times. There is a process of change and rationalization of the system, reducing the number of higher educational institutions.

There is increased competition among traditional universities. Visiting the websites of institutes and universities it can be found concentrated efforts on branding and marketing of these institutions. With increasing competition for potential consumers of educational "ser-

\footnotetext{
*Corresponding author: miillen@rambler.ru
} 
vices, intangible factors and marketing tools are becoming increasingly important, among them the image of university. Customers need to something, there they can not be offered elsewhere. Competitive advantage provides an approach to a client as the main priority, $\mathrm{K}$. according to K. Crawford, H. M. Hasan because if the majority of customers are not satisfied with the services provided, there is no point for an organization to continue its activities [1].

Unlimited possibilities of the information age and free access to Internet allows students to continue their education in institutions in different parts of the world, without leaving your home, according to E. Mark [2]. All these factors make the sphere of higher education is very competitive.

More and more pressure from different sides are given to higher education institutions, so that they would correspond the world level and become competitive, reach the effective learning process, and provide the economy with high-quality personnel. J.L. Bess and J.R. Dee consider the quality of customers' (students') service is one of the basic elements of a world-class higher education institutions [3].

The quality of education at the present stage can be considered, by F. Khodayari, B. Khodayari, as the main competitive advantage of higher educational institutions, along with the cost of learning. The quality of education is a set of consumer properties of educational services, providing the opportunity to meet the learner's needs in the comprehensive development of personality [4].

According to E.A. Shnyrenkov and I.P. Pryadko, in order to effectively guarantee the quality of higher education it is very important that educational institutions have available means of collecting and analyzing information about their own activities, in the absence of which the universities are not able to identify the strengths and weaknesses of its activities and the results of innovation [5]. Information systems relating to quality, should cover at least the following questions: satisfaction of students with educational programs, teaching effectiveness, accessibility and cost of training resources, the main indicators of the university work.

It is worth paying attention to a number of factors influencing the choice by applicants of higher education institutions. The most important are: the reputation of the institution, teachers or faculty (department), recommendations of friends. Although there are other significant factors, such as career prospects, the prestige of professions, sports facilities, accommodation of alma mater, relatives that affect the choice, it is obvious the following: all that the organization offers in terms of quality and complete service package, has the main significance [6].

As $\mathrm{H}$. Shahid and O. Shafique stated, the uniqueness and peculiarity of university as a specific organization is that the majority of customers (learners) are inside of it. External clients are employers, applicants and their parents [7]. But as soon as the applicant becomes a student, he is exposed to the organizational culture of the university, its traditions, norms and values.

J. Heskett and W. Sasser described a model "chain "service — profit", the effect of satisfaction of an employee and consumer. According to them, this model provides a ground that can be used to operationalize the strategies to increase the quality of the current level of customer service to a level that meets the requirements of international class. The structure of the international level organization has the following features: 1) most important - care for the client; 2) participatory management; 3 ) the remuneration system is aimed at prevention rather than correction; 4) long-term goals; 5) partnership development; 6) a new culture of thinking and goal setting; 7) involvement of employees and personnel development as shared values of organization; 8) assessing performance; 9) flat organizational structure, minimization levels of management; 10) structured tasks [8]. At present in Russia there is a task before universities of improving their competitiveness, which actualize the problem of 
increasing an efficiency of activities of higher education institutions. And a key factor in solving this problem can be seen the organizational culture. J. Heskett described the competitive advantages of the University, that can be identified: 1) a quite wide range of educational profiles and specialties (baccalaureate and magistracy); 2) high qualification of the teaching staff; 3) linkages with companies-employers; 4) positive image and reputation in the region and among other universities. Currently, universities are not only engaged in educational and scientific process, but also in business activities, attracting funds from various sources [9].

University is a complex structural unit that performs a number of functions: educational, educative, scientific, social, economic, has a rather complicated management system. B. Fralinger outlined the following characteristics of an university: 1) a plurality of performance goals and complexity of the system of interrelated processes, diversity of structural units, interacting with external agencies, organizations and enterprises; 2) multidisciplinary university system and strong relationship of managing processes that requires coordination of administrative decisions between different activities; 3) management of university has been always provided a global feedback, usually via the environment, in which the results of activities of university are shown, form its image, make up its authority as an educational, scientific and cultural center; 4) high inertia of the university as a system as well as the results of its activity occur after a sufficiently long period of time; 5) widespread use the information technologies in activity of an university [10].

Elements such as customer service and organizational culture should also be studied in the context of the higher education environment in order to develop a strategy to meet the expectations of work and study at the university, to create the prerequisites for success in globalized market.

E. Schein believes that organizational culture is a set of basic assumptions, inventions, discovered or developed by a group to learn how to cope with problems of external adaptation, internal integration, functioning long enough to prove their worth, and be transmitted to the new members of organization as the only correct [11]. From the perspective of sociology of management, organizational culture is a system of formal and informal rules and norms of activity, individual and group interests, customs and traditions prevailing in the organization.

Regardless of individual point of view on the organizational culture, E. Khripko believes that organizational culture exists in any organization and plays an important role in the success or failure of organization, it can not be considered in isolation from the concept of customer service [12].

Typically, the organizational culture is a complex set of ideas, taken for granted by members of a collective and defining the general framework of behavior. M. Alvesson proposed the idea that the behavior of people in organization should not only enhance its value, but rather the organizational culture must be designed as a driving force for customer service [13].

V. Kovač et al. note that the organizational culture of the university appears as a system of values, customs, traditions, attitudes, shared by the various categories of employees and students of the university [14]. These components are expressed in the norms, samples, standards and stereotypes of thinking and activities that occur in patterns of behavior and attitudes, as well as the mutual expectations of managers, employees, students. The components of organizational culture influence the quality of education at the university.

According to Ishkov A.D. et al., the organizational culture as a complex formation is made up of many cultures (facets): corporate, personnel, managerial, innovative, business, educational, legal, communicational, that reflect the different sides of an organization [15]. 
A more detailed examination of the problem of subcultures in the organizational culture of the university allows everyone to select the following types of subcultures: subcultures of the administrative and managerial staff, faculty, educational support personnel, other categories of staff, students, postgraduates. It is obvious that the facets of the organizational culture and its subcultures are coexisting and simultaneously interacting subsystems.

\section{Materials and Methods}

The study was conducted at the Moscow State University of Civil Engineering (NIU "MGSU"), the sample consisted of the following groups: teaching staff, teaching support staff and students, who study on the profile "Construction". Employees spend most of their working day interacting with students. They have expressed their opinions about the organizational culture and the satisfaction of employees. The study involved 192 people.

In this study three measuring methods are applied. The first one focused on the measurement of the components of organizational culture, and the second one evaluated the job satisfaction of employees, the third one measured the level of satisfaction of learners.

Questionnaire of assessing organization culture, developed by B. Van der Post and coworkers [16], adapted by the author, was used to assess the organizational culture.

Questionnaire includes the following scales: customer focus, tendency to innovations, employee participation in management of the organization, clarity of objectives of the organization, identification with the organization, distribution of management authorities between the administrative staff (localization of power); management style; integration in the organization (relationships within the collective); focus on performance (tasks) / relationships; focus on remuneration; resolution of the conflicts.

The abbreviated version of the Minnesota Satisfaction Questionnaire developed by D. Weiss and colleagues, an adaptation of J. Jewell et al. was used to iidentify the level of job satisfaction among employees [17]. This measuring tool is pretty simple and straightforward. It contains twenty items covering a wide range of issues that relate to working process. These items include the ability to be busy all the time, the ability to work alone, the opportunity to do something for others and the ability to perform a various types of work; ways in which the policy of organization is applied in practice, compliance with wage and volume of work performed, career chances, the number of rewards for a well done work.

Student ssatisfaction qquestionnaire was originally developed on the basis of a qualitative analysis of the comments written by graduates of the University of Civil Engineering (NIU "MGSU"). On the basis of the two groups of consumer satisfaction indicators: 1) score or index of customer satisfaction; 2) availability of personnel for a consumer, the following indicators of student satisfaction were determined and tested: the quality of training programs and their content; the results of training programs; the ratio of the administration, faculty and staff; assistance in training of the university staff; student services (library, information support of educational and extra-curricular activities, health); participate in the work of the Student Council; scientific publications of students.

All items of questionnaires were presented positively, formulated in simple and accessible language. Respondents were asked to evaluate their answers on a five-point Likert scale ( 1 - absolutely disagree, 2 - disagree, 3 - difficult to say, 4 - agree and 5 strongly agree).

For data collection we were use a structured survey, on a voluntary basis, anonymously. Questionnaires were sent to university employees, took training programs and through the internal communication system to different departments. The survey of students was conducted during classes. 
Keeping in mind that the problem of the study was to identify factors influencing the culture of service of students in higher education institution of civil engineering, and in order to obtain significant results, there was conducted statistical analysis: descriptive statistics for quantitative variables in the questionnaires; frequency analysis of the points of questionnaire for assessing components of organizational culture; rank and order correlation [18] to find relationships between the components of organizational culture, job satisfaction of employees and students' satisfaction of learning.

\section{Results}

Various indicators of organizational culture were evaluated by respondents-employees as follows: customer focus (average -4.9 ), tendency to innovations (4.8), identification with the organization (4.75), focus on performance (tasks) (4.72), focus on relationships (4.4). At the lower end of the spectrum the tasks structure was evaluated as the lowest (3.3), following the localization of power (3.8), the relationship within the collective (4.1), conflict resolution (4.15), and participatory management style $(4,2)$. Possible ranges of values were from 1 (the lowest) to 5 (the highest).

Results for the job satisfaction of employees are given below. The high indicators was achieved by points: the opportunity to be busy all the time $(81 \%)$, the ability to work alone (80.6\%), the opportunity to do something for others $(80.1 \%)$ and the ability to perform a various types of work (79\%). Low rates: ways in which the policy of organization is applied in practice $(55.9 \%)$, compliance with wage and volume of work performed $(44.5 \%)$, career chances $(38.7 \%)$, the number of rewards for a work well done $(58 \%)$.

Average values of indicators of students' satisfaction of learning process (based on Likert scale from 1 to 5) were distributed as follows: training program results (3.66), the quality of training programs and their content (3.61), assistance in learning of university staff $(3,47)$, the ratio of the administration, faculty and staff (3.28), student services (3.28), technical equipment (3.21), participation in the work of the Student Council (2.89).

Analysis by rank correlation indicated that there were not significant correlations between variables at the significance level of $\mathrm{p}<0.1$. Only the correlation between organizational culture and satisfaction of students was significant. Unlike employees, students showed more unanimity in the positive perception of the university and positively evaluated its activities as a whole. The results did not confirm the relationship between organizational culture and job satisfaction, although the close relationship between corporate culture and job satisfaction could be expected on the basis of the study of literature. The interaction between organizational culture and satisfaction of students was significant, there was expressed trend relating to the fact that there was attached a great importance to quality, services provided to students. These services are important for the university. Focusing on a student was an integral index, which on the basis of the survey received the highest rating.

\section{Discussion}

It should be remembered that the key variables of sphere of higher education are manifested both in external and internal levels. On the external level, there is increasing competition with private institutions of higher education, a change of policy in regard to the sphere of higher education and attempts to ensure its quality, universal access to higher education. At the internal level (one organization) it can be implemented programs to promote the quality of higher education in terms of processes and procedures, the quality of academic programs, there is a care and maintenance of learners, providing services by employees in 
carrying out their tasks, providing auxiliary equipment - all those aspects which should promote customer service, and will have an impact on the ability of educational institutions to compete effectively. It was assumed that the issues of organizational culture associated with satisfaction and support for students facing the external environment. Areas of dissatisfaction of the staff manifested in the low career chances, low wages and hard work. The organization policy can be implemented in the direction of job enrichment, this approach is essentially intra-organizational and has no relation to the broad aspects of organizational culture and the issues of satisfaction of students.

Organizational culture of a university has a distinctive feature associated with the presence of a large number of students, which is significantly updated annually contingent. Therefore, the organizational culture of the university appears as series of organizational subcultures (micro-cultures), at least, there is subcultures of permanent employees and students. Positive perception of the image and reputation of the University, elements of the University's organizational culture by the majority of university staff and students leads to increase the satisfaction and quality of education.

It was assumed that the relationship and interaction between teachers (employees) and learners (customers) could not be the same as in the case of usual business in environment. The learner not only a customer, but also a "product" of the learning process, it assumes a leadership and mentoring relationships that bring a new dimension to ensuring a clean customer service. Employees and students are not moving in their development at the same directions and get satisfaction of various factors.

\section{Conclusions}

Organizational culture of a university is a multilevel system, forming under influence of a variety of factors of external and internal environment. Since organizational culture defines the organizational style of activity [19], including management style, the study of existing organizational culture, the possible ways of its development and improvement is necessary and requires integrated approach.

The results indicate that organizational culture of higher education institutions of civil engineering perceives the importance of customer requests. A strong emphasis of the staff on executive may weaken other aspects of organizational culture that would contribute to its strengthening, for example, the involvement of staff, focus on remuneration, management style, and conflict resolution. The relationship between staff and students can be better structured, which should help increasing satisfaction and attracting and retaining students in the university. The development of organizational culture of the university provides more efficient activity of the organization, enhance the quality of education, reputation and image of the university; allow each member of the teaching staff to determine the possibility of achieving their greatest career success and his own reputation (as a researcher and as a teacher), and the university as a whole.

Organizational Culture of the university is a multi-level system, is influenced by numerous factors of external and internal environment. Further study of the components of the existing organizational culture, the possible ways of its development and improvement is necessary and requires an integrated approach.

\section{References}

1. K. Crawford, H.M. Hasan, L. Warne, H. Linger, Emergence: Complexity and Organization, 11(1), 1-18 (2009)

2. E. Mark, Journal of Higher Education Policy and Management, 35(1) 2-10 (2013) 
3. J.L. Bess, J.R. Dee, Understanding College and University Organization: Theories for Effective Policy and Practice (2012)

4. F. Khodayari, B. Khodayari, Interdisciplinary Journal of Research in Business, 1(9) 38-46 (2011)

5. E.A. Shnyrenkov, I.P. Pryadko, Procedia Engineering. 117, 325-330 (2015)

6. G. Wells, A. Edwards, Pedagogy in Higher Education: A Cultural Historical Approach (N-Y., 2013)

7. H. Shahid, O. Shafique, O.H. Bodla, Research on Humanities and Social Sciences, 2(10) 64-67 (2012)

8. T. Bush, L. Bell, D. Middlewood Principles of Educational Leadership \& Management (Middlewood, London: Sage, 2009)

9. P. Kotter, J.L. Heskett Corporative culture and performance (Free Press, 2011)

10. B. Fralinger, Journal of College Teaching \& Learning, 11(4) (2007)

11. E.H. Schein, Organizational culture and leadership. (San Francisco: Jossey-Bass, 2004)

12. E. Khripko, Matec web of conferences, 73, 07021 (2016)

13. M. Alvesson, Organizational culture: Meaning, discourse, and identity. In Ashkanasy, N.., Wilderom, C., \& M. Peterson (Eds.) The handbook of organizational culture and climate. (Thousand Oaks, CA: Sage Publications, $2^{\text {nd }}$ ed., 2011) Pp. 11-28

14. V. Kovač, J. Ledić, B. Rafajec, Understanding University Organizational Culture, (Frankfurt am Main: Peter Lang, 2006)

15. A.D. Ishkov, M.Y. Mishlanova, K.P. Grabovyi, International Journal of Applied Engineering Research, 11(3) 1676-1679 (2016)

16. N. Ashkanasy, C. Wilderom, M. Peterson Handbook of organizational culture and climate. (London: Sage, 2011)

17. P. Lester, D. Inman, L. Bishop, Handbook of Test and Measurement in Education and Social Sciences (London, 2014)

18. D.C. Howell. Statistical Methods for Psychology, (Wadsworth, Cengage Learning, 2013)

19. N.G. Miloradova, A.D. Ishkov, Advanced Materials Research, 1065-1069. 2538-2541 (2015) 